\title{
Research on Football Club Fans Consumption Development Influence Factors
}

\author{
Qihui Wang and Fenghua Zheng*
}

Department of Physical Education, Ningbo University of Technology, Ningbo 315211, Zhejiang, China

\begin{abstract}
As world cup is now behind us, fans excitement can also slightly calm down, contemporary social fans are important parts in China football development. The paper bases on specific analyses of Chinese fans specific conditions, football clubs consumption situations, puts forward that with fusion of football culture in the world, Chinese football clubs amount has increased, operational mode has changed, which mainly maintain clubs normal operation by competition revenue, television relay revenue and business revenue. Secondly, through analyzing Chinese fans composition status, the paper gets that among Chinese fans, men fans account for $78 \%$, most of them are 40 to 50 years old people that have enough purchasing power to football goods, which conforms to Chinese residents' characteristics. Finally, utilize fuzzy mathematical evaluation method to evaluate Chinese football clubs fans consumption development and further get conclusions that in evaluation on China football clubs development, the number of fans is uppermost factor that affects China football clubs development, China must strengthen investment in football undertaking, reinforce football level, improve ranking, and only then can arouse national supports for China football and further be beneficial to China football development.
\end{abstract}

Keywords: Fans consumption, football club, fuzzy mathematical evaluation, operational mode.

\section{INTRODUCTION}

As football entering into China, Chinese fans' roles also have huge changes, below are relevant scholars research results on Chinese fans consumption situations [1].

Wu Zhi-Peng in the article "Shan'xi Baorong Chanba football club fans consumption behavior and consumption trend research", pointed out that Chinese football club was a emerging industry, with regard to western European countries, its cultural gap was larger. As football entered into domestic market, fans directly purchased football relevant products and clubs offered football products that became maximum consumers in China football [2]. Tang Yu in the article " Research on football consumption behavior to football clubs operation influence", by exploring Chinese fans consumption status, pointed out that due to China football recent years' techniques were just so-so [3], performances relatively declined, which caused Chinese fans' purchasing power on national football clothes, shoes, cuff and other football products being declined, and let Chinese fans capita being greatly flown into foreigners and was bad for China football development [4].

Tao Feng in the article "Jiangxi province professional football clubs sustainable development countermeasures research", in the research on Zhejiang province professional football clubs' sustainable development research [5], he based on social investigation and gained first-hand investigation data [6], conducted specific research on China's football clubs management and found that with development of globalization, mutual fusion among all countries football clubs cultures, Chinese clubs have gained certain development, referenced world and other European and American countries football clubs' management models, as well as propelled to China football clubs development [7].

By visiting relevant scholars, learning China football position in world football, combining with lots of document literature, the paper carries on further research and analysis of Chinese fans consumption situation.

\section{MODEL ESTABLISHMENTS}

By investigating and researching on all clubs, it analyzes Chinese football clubs revenue situation from 2011 to 2014 and gets following Table $\mathbf{1}$ and Table 2:

Table 1. Chinese football clubs' revenue situation from 2011 to 2014.

\begin{tabular}{|c|c|c|c|}
\hline $\begin{array}{c}\text { Revenue } \\
\text { situation }\end{array}$ & $\begin{array}{c}\text { Game } \\
\text { revenue }\end{array}$ & $\begin{array}{c}\text { Television } \\
\text { relay revenue }\end{array}$ & $\begin{array}{c}\text { Business } \\
\text { income }\end{array}$ \\
\hline \hline 2011 & $40 \%$ & $24 \%$ & $36 \%$ \\
\hline 2012 & $38 \%$ & $36 \%$ & $26 \%$ \\
\hline 2013 & $42 \%$ & $33 \%$ & $25 \%$ \\
\hline 2014 & $36 \%$ & $38 \%$ & $26 \%$ \\
\hline
\end{tabular}

The paper analyzes Chinese clubs' revenue situation and Manchester United as well as Real Madrid revenue situation (as Fig. (1) and Fig. (2), and gets that game revenue accounted for $40 \%$ in 2011, while television relay revenue arrived at 38\% in 2014; comparing Manchester United with Real Madrid, the two clubs revenue situations are different, 
Manchester United bases on other operating income, while Real Madrid bases on commodity sales.

Table 2. Manchester United and Real Madrid clubs' revenue comparison.

\begin{tabular}{|c|c|c|c|}
\hline $\begin{array}{c}\text { Revenue } \\
\text { situation }\end{array}$ & Tickets & $\begin{array}{c}\text { Commodity } \\
\text { sales }\end{array}$ & $\begin{array}{c}\text { Other } \\
\text { operating income }\end{array}$ \\
\hline \hline $\begin{array}{c}\text { Manchester } \\
\text { United }\end{array}$ & 58 & 33 & 88 \\
\hline Real Madrid & 21 & 87 & 50 \\
\hline
\end{tabular}

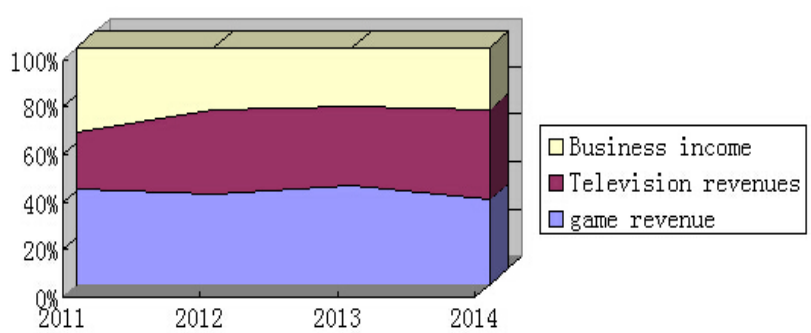

Fig. (1). Income of football clubs in China in 2011-2014.

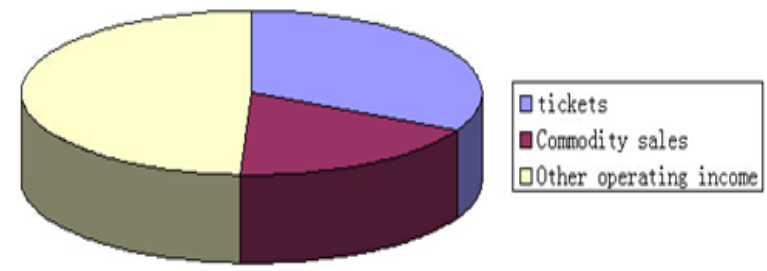

Fig. (2). Manchester united and real Madrid club revenues.

\subsection{Fans Situation in Chinese Football Clubs}

Only conduct specific researches on different kinds of people groups in Chinese clubs then would be beneficial to China's regular management in football clubs, relevant data is as Table $\mathbf{3}$, Table $\mathbf{4}$ and Table $\mathbf{5}$.

By above net-form Fig. (3), bubble-form Fig. (4), pieform Fig. (5) analyses, it points out that among fans, residents that are around 45 years old account for $48 \%$, in different education level proportions, senior high school and technical secondary school account for $26.9 \%$, in fans revenue situation, the number of people with 1501 to 2000 income are a lot, which conforms to characteristics that such class residents in China has more leisure time.

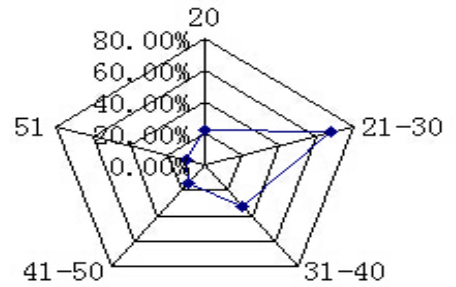

- proportion $(\%)$

Fig. (3). Proportion of different age.

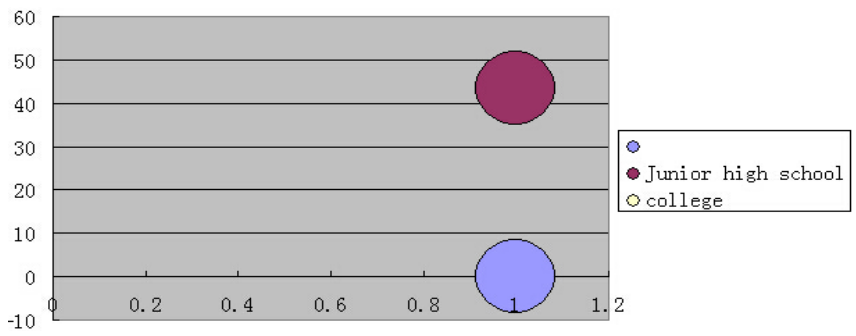

Fig. (4). Fans of different cultural levels.

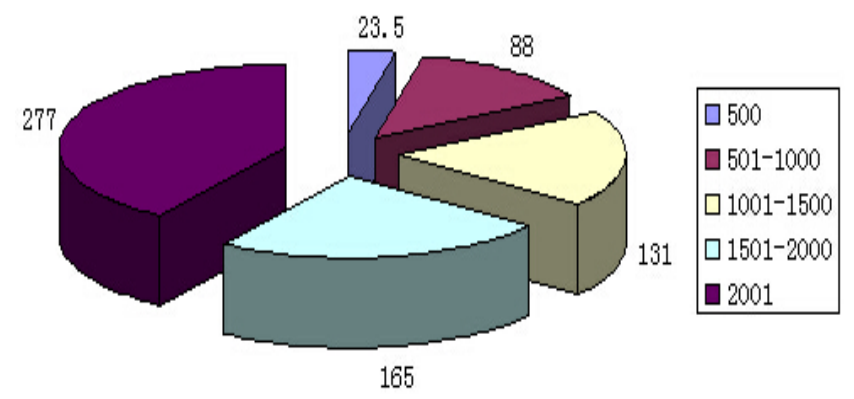

Fig. (5). Fans income and consumption.

\subsection{Fans Consumption Influence Factors Analysis}

Factors that affect China's clubs fans consumption are quite a lot, it mainly includes personal factor, social factor, family factor, and cultural factor and so on. Below Table 6 is main factors' analysis.

Table 3. Different age groups obtained proportions.

\begin{tabular}{|c|c|c|c|c|}
\hline Age & Number of people & Number of fans & $\begin{array}{c}\text { Proportion of total investigate } \\
\text { number of people }\end{array}$ & $\begin{array}{c}\text { Proportion of the age group's } \\
\text { number of people (\%) }\end{array}$ \\
\hline \hline Below 20 years old & 36 & 8 & 4.9 & 22.2 \\
\hline $21-30$ & 183 & 123 & 75.5 & 67.2 \\
\hline $31-40$ & 83 & 27 & 16.6 & 32.5 \\
\hline $41-50$ & 26 & 3 & 1.8 & 14.5 \\
\hline Above 51 & 22 & 2 & 1.2 & 9.1 \\
\hline Total & 350 & 163 & & \\
\hline
\end{tabular}


Table 4. Different education levels' fans proportions.

\begin{tabular}{|c|c|c|c|c|}
\hline Age & Number of people & Number of fans & $\begin{array}{c}\text { Proportion of investigate total } \\
\text { number of people }\end{array}$ & $\begin{array}{c}\text { Proportion of number of people } \\
\text { in education level (\%) }\end{array}$ \\
\hline \hline Primary school & 11 & 5 & 3.1 & 45.5 \\
\hline Junior high school & 83 & 36 & 22.1 & 43.4 \\
\hline $\begin{array}{c}\text { Senior high school, technical } \\
\text { secondary school }\end{array}$ & 98 & 44 & 26.9 & 44.9 \\
\hline University and above & 158 & 78 & 17.9 & 49.4 \\
\hline Total & 350 & 163 & & \\
\hline
\end{tabular}

Table 5. Fans revenue and consumption situations.

\begin{tabular}{|c|c|c|c|}
\hline Monthly revenue & Number of people & Number of fans & Football consumption mean value \\
\hline \hline Below 500 & 23 & 8 & 23.5 \\
\hline $501-1000$ & 167 & 93 & 88 \\
\hline $1001-1500$ & 41 & 22 & 131 \\
\hline $1501-2000$ & 77 & 28 & 165 \\
\hline Above 2001 & 42 & 163 & 277 \\
\hline Total & 350 & & \\
\hline
\end{tabular}

Table 6. Fans consumption influence situation.

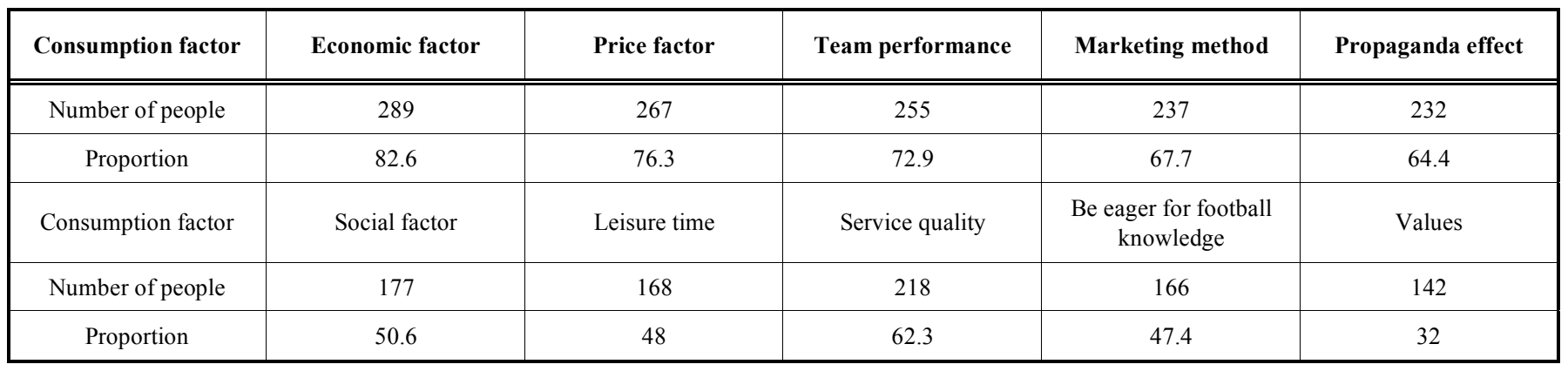

Table 7. Fans sex ratio.

\begin{tabular}{|c|c|c|}
\hline & Female & Male \\
\hline \hline Number of people & 12 & 97 \\
\hline Proportion(\%) & $9.43 \%$ & $90.57 \%$ \\
\hline
\end{tabular}

According to above Table 7, analyze Fig. (6) and Fig. (7) and get that among Chinese fans, male covers 90.57\%; Main factors that affect fans consumption situation are price factor, team factor, marketing method and so on, from which economic factor is uppermost factor that affects Chinese fans consumption.

\subsection{Situation of Fans Acquiring Football Games Infor- mation}

As Chinese scientific and technological information era develops, Chinese fans have many paths to acquire football games information, including acquires game information through family and friends' introduction, and by advertisement.

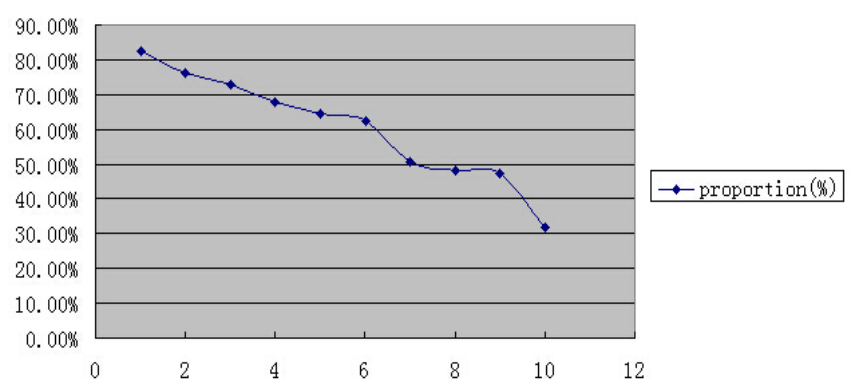

Fig. (6). Consumption influence fans. 


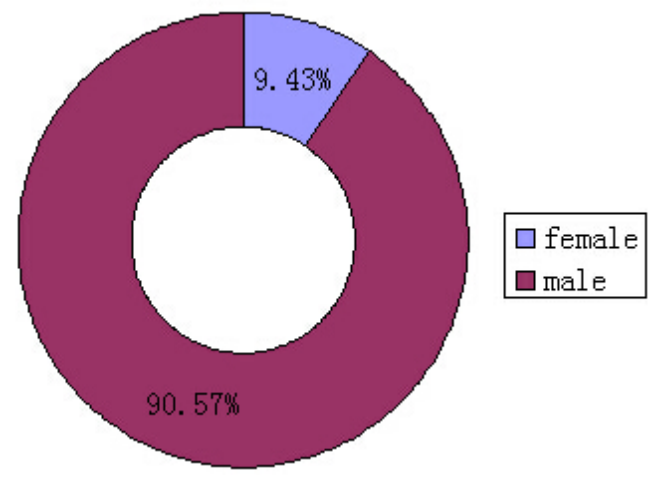

Fig. (7). Fans sex ratio.

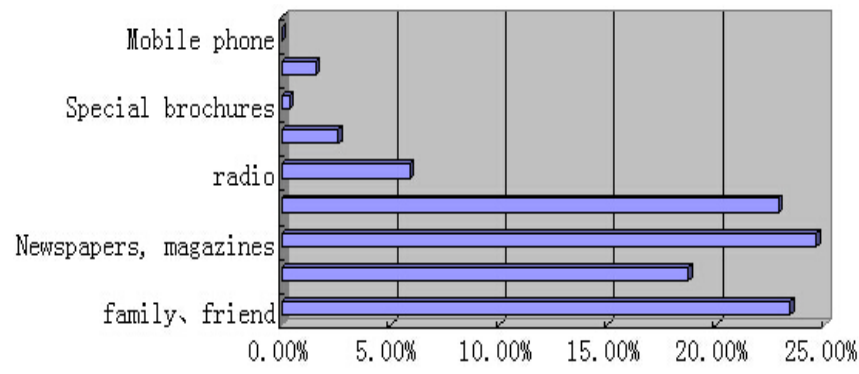

Fig. (8). Fans get game information way.

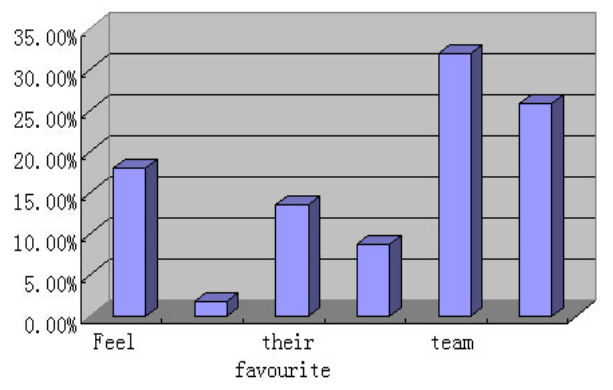

Fig. (9). The fans watching situation list.

By above Table 8 and Table 9 researches, analyze Fig. (8) and Fig. (9) and get that China's fans acquiring game information through broadcast, television, newspapers and else account for $65 \%$, it shows most of people in Chinese fans still acquire information by traditional way; reasons for fans watching game are different, from which cheer for one's favorite team accounts for $31.95 \%$, and secondly is loving football that accounts for $25.82 \%$.

\section{FUZZY EVALUATION METHOD-BASED CHI- NESE FANS CONSUMPTION SITUATION COM- PREHENSIVE EVALUATION}

Fuzzy evaluation is a method that conducting comprehensive evaluation from the perspective of quantity, its application scope in real life is very extensive. It bases on fuzzy mathematics, applies fuzzy mathematical principles, establishes multiple influence factors' indicator set, calculates indicators' weights and compares weights by fuzzy algorithm and then defines evaluation matrix, utilizes maximum membership principle to finally define importance extent.
Table 8. Situation of fans acquiring game information paths.

\begin{tabular}{|c|c|c|}
\hline Information source path & $\begin{array}{c}\text { Selection } \\
\text { rate (\%) }\end{array}$ & Ranking \\
\hline \hline $\begin{array}{c}\text { Family, friends and colleagues' intro- } \\
\text { duction }\end{array}$ & 23.40 & 2 \\
\hline $\begin{array}{c}\text { Television publicity and introduction or } \\
\text { television advertisement }\end{array}$ & 18.72 & 4 \\
\hline Newspapers, magazines & 24.61 & 1 \\
\hline Internet & 22.88 & 3 \\
\hline Radio broadcasting & 5.89 & 5 \\
\hline Outdoor advertising and posters & 2.60 & 6 \\
\hline Special brochures & 0.35 & 8 \\
\hline Advocacy advertising on the back of \\
tickets & 1.56 & 7 \\
\hline Mobile phone & 0.00 & 9 \\
\hline
\end{tabular}

Table 9. Fans watching situation table.

\begin{tabular}{|c|c|c|}
\hline Watching motivation & $\begin{array}{c}\text { Selection } \\
\text { rate (\%) }\end{array}$ & Ranking \\
\hline \hline $\begin{array}{c}\text { Take in the atmosphere, relax and enter- } \\
\text { tainment }\end{array}$ & $18.02 \%$ & 3 \\
\hline Team tactics are advanced & $1.86 \%$ & 6 \\
\hline $\begin{array}{c}\text { There are favorite football players in } \\
\text { team }\end{array}$ & $13.59 \%$ & 4 \\
\hline Support China football & $8.72 \%$ & 5 \\
\hline Cheer for the team & $31.95 \%$ & 1 \\
\hline Love football & $25.82 \%$ & 2 \\
\hline
\end{tabular}

\subsection{Define Evaluation Indicator Set}

On the basis of above correlation analysis, and consult lots of document literature, finally it defines number of fans, consumption situation, and clubs' comprehensive level as evaluation indicators, according to:

$U=\left\{u_{1}, u_{2}, \cdots, u_{m}\right\}, m=1,2,3$,

Evaluation indicator set is $=\{$ number of fans、consumption situation、 clubs' comprehensive level\}.

\subsection{Define Evaluation Grade Set}

For systematic evaluation grade, mainly determination method is expert evaluation method. In Chinese fans consumption development evaluation, their evaluation grade set is as following, according to:

$V=\left\{v_{1}, v_{2}, \cdots, v_{n}\right\}, n=1,2,3,4$ 
Chinese fans consumption evaluation grade set is $=\{$ more, some, general, little\}.

\subsection{Define Each Evaluation Indicator Weight}

Weight main expression method is:

$w=\left\{\mu_{1}, \mu_{2}, \cdots, \mu_{m}\right\}, m=1,2,3$

Among them: $\sum_{m=1}^{6} \mu_{m}=1$

Define evaluation indicator weight method mainly has analytic hierarchy process and normalization method, from which normalization method is as following:

$w_{i}=\frac{\frac{C_{i}}{\overline{S_{i}}}}{\sum_{i=1}^{n} \frac{C_{i}}{\overline{S_{i}}}},(i=1,2, \cdots, m)$

Among them, $w_{i}$ is evaluation parameter $i$ monitoring value; $\bar{S}_{i}$ is evaluation parameter $i$ grade $m$ criterion arithmetic average value, then weight set is:

$w=\left\{w_{1}, w_{2}, \cdots, w_{m}\right\} 。$

Here, apply normalization method to calculate weights, result is:

$w=\{0.5, \quad 0.3, \quad 0.2\}$

\subsection{Define Evaluation Matrix}

Comprehensive evaluation matrix $R$ evaluation method is mainly experts' evaluation method, analytic hierarchy process, membership function method. So as to let computed result to be more accurate, here uses membership function method, define fuzzy relation matrix $R$, from which:

$R=\left(R_{1}, \quad R_{2}, \quad R_{3}\right)^{T}$

(1) For the 1 grade evaluation grade

$\mu_{i 1\left(u_{i}\right)}=\left\{\begin{array}{cc}0 & u_{i} \geq v_{i 2} \\ -\frac{u_{i}-v_{i 2}}{v_{i 2}-v_{i 1}} & v_{i 1}<u_{i}<v_{i 2} \\ 1 & u_{i} \leq v_{i 1}\end{array}\right.$

(2) For the $j$ grade evaluation grade

$$
\mu_{i j\left(u_{i}\right)}=\left\{\begin{array}{cc}
0 & u_{i} \leq v_{i j-1} \text { or } u_{i} \geq v_{i j+1} \\
\frac{u_{i}-v_{i j-1}}{v_{i j}-v_{i j-1}} & v_{i j-1}<u_{i}<v_{i j} \\
-\frac{u_{i}-v_{i j+1}}{v_{i j+1}-v_{i j}} & v_{i j} \leq u_{i}<v_{i j+1}
\end{array}\right.
$$

(3) For the $n$ grade evaluation grade

$\mu_{i n\left(u_{i}\right)}=\left\{\begin{array}{cc}0 & u_{i} \leq v_{i n-1} \\ \frac{u_{i}-v_{i n-1}}{v_{i n}-v_{i n-1}} & v_{i n-1}<u_{i}<v_{i n} \\ 1 & u_{i} \geq v_{i n}\end{array}\right.$

Input data into above each parameter's each grade standard membership function formula, it can solve each evaluation parameter membership to each evaluation grade, and then construct fuzzy relation matrix $R$.

Computed result

$R_{1}=(0.6,0.3,0.1)$;

$R_{2}=\left(\begin{array}{lll}0.7, & 0.2,0.1\end{array}\right)$;

$R_{3}=\left(\begin{array}{lll}0.6, & 0.25,0.15\end{array}\right)$

\subsection{Carry on Comprehensive Evaluation}

\section{Known}

$W=\left(\mu_{j}\right)_{1 \times m}, R=\left(r_{j i}\right)_{m \times n}$,

by

$S=w \circ R=\left(\mu_{1}, \mu_{2}, \cdots, \mu_{m}\right) \cdot\left(\begin{array}{cccc}r_{11} & r_{12} & \cdots & r_{1 n} \\ r_{21} & r_{22} & \cdots & r_{2 n} \\ \vdots & \vdots & \vdots & \vdots \\ r_{m 1} & r_{m 2} & \cdots & r_{m n}\end{array}\right)$

$=\left(s_{1}, s_{2}, \cdots, s_{n}\right)$

It can get fuzzy evaluation set $S$, from which "o" is fuzzy composition operator. $M(\cdot, \oplus)$ Operator reflects that weight function is more obvious than other operators, and its comprehensive extent is stronger, as well as most sufficient utilize $R$ information that belongs to weighted average type, its handling with data is relative more accurate. Therefore, here take fuzzy operator as $M(\cdot, \oplus)$ operator that :

$s_{k}=\min \left(1, \sum_{j=1}^{m} \mu_{j} r_{j k}\right), k=1,2, \cdots, n$

Input above computed result into above formula and can get:

$S=\left(\begin{array}{lll}0.45, & 0.37 & 0.18\end{array}\right)$

By fuzzy evaluation vector $S$ analysis, it makes comprehensive conclusion. Generally, it can adopt maximum membership principle, weighted average principle, fuzzy vector uniformization, in order to make computed result to be more accurate and closer to theoretical practical conclusions, here it applies maximum membership principle to conduct comprehensive evaluation on evaluation vector $S$.

For maximum membership principle, if given fuzzy evaluation set

$S=\left(S_{1}, S_{2}, \cdots, S_{n}\right)$, 
(from which $S_{i}$ is grade ${ }^{v_{i}}$ membership to fuzzy evaluation set ), $M=\max \left(S_{1}, S_{2} \cdots, S_{n}\right), M$ corresponding element is evaluation result of comprehensive evaluation.

By

$S=\left(\begin{array}{lll}0.67, & 0.42 & 0.33\end{array}\right)$,

it is clear:

$M=\max \left(S_{1}, S_{2}, \cdots, S_{n}\right)=0.67$

Therefore, in Chinese football clubs' fans consumption situation evaluation, the number of fans is uppermost factor in Chinese fans consumption situation. As the number of fans increases, it will drive China football clubs' development to provide guarantee for China football undertaking.

\section{CONCLUSION}

Firstly, the paper carries on investigation and research on Chinese some football clubs and gets that clubs' revenue source are game revenue, television relay revenue, business revenue and so on, different clubs' revenue inclinations are different, such as main revenue in Real Madrid revenue is commodity sales that brings into huge profits to club development.

Secondly, it studies Chinese clubs' fans specific situation and points out that among Chinese fans, though female fans amount has increased, male fans still cover above $78 \%$, most of them are staff that go in for public institution, freelance at the age of around 40 to 50 years old, which conforms to characteristics of men's more leisure time, having stable life and owing more plentiful revenue, so the group of people around the age of 30 becomes the potential object in China's football propaganda.

Finally, the paper uses fuzzy mathematics evaluation method, defines that fans consumption situation influence factors in Chinese football clubs to evaluate and gets conclusions: the number of fans is the main factor that affects China football clubs' fans consumption, so China should increase investment in football undertaking, strengthen China football level, enhance international ranking so that will be helpful for China football further development.

\section{CONFLICT OF INTEREST}

The authors confirm that this article content has no conflict of interest.

\section{ACKNOWLEDGEMENTS}

Declared none.

\section{REFERENCES}

[1] N. Chen, "Harmonious society calls for society harmonious GDP," Journal of Yunnan Finance and Trade Institute, vol. 21, no. 6, pp. 81-85, 2005.

[2] L. Fan, and J. Liang, "The development of the economy and society calls to create the new mode of economic development: "green and harmonious" development," Value Engineering, vol. 25, no. 5, pp. 29-31, 2006.

[3] C. Liu, B. Guan, "Power of harmony-against the background of chinese culture," Journal of Tianjin University(Social Sciences), vol. 11, no. 5, pp. 453- 457, 2009.

[4] J. Lu, "The two states of tao and the two forms of object," Journal of Anhui University(Philosophy \& Social Sciences), vol. 30, no. 6, pp. 5-6, 2006.

[5] B. Su, Z. Liu, and C. Liu, "Manifesto of harmonious ethics--for harmonious development of living beings and abiotic existence," Journal of Jinan University, vol. 12, no. 5, pp. 1-10, 2002. 12(5): 110 .

[6] W. Xiaoguang, Thoughts and Analyses of the Construction of Harmonious Enterprises in China. Research On Development, China, 2007.

[7] X. Xu, "Reflections on the modern value of the ideas of lao zi," Journal of Anhui University(Philosophy \& Social Sciences), vol. 30, no. 6, pp. 6-8, 2006. 